\title{
Factors associated with poor adherence amongst patients receiving antiretroviral therapy at the Oshakati intermediate hospital in Namibia
}

\author{
Maria Francineth Bauleth*1, Brian Van Wyk ${ }^{1}$, Daniel Opotamutale Ashipala ${ }^{2}$ \\ ${ }^{1}$ Faculty of Community and Health, School of Public Health, University of the Western Cape, Cape Town, South Africa \\ ${ }^{2}$ Department of General Nursing Science, School of Nursing, Faculty of Health Sciences, University of Namibia (UNAM), \\ Keetmanshoop, Namibia
}

Received: October 9, 2016

Accepted: November 1, 2016

Online Published: November 15, 2016

DOI: $10.5430 / i j h . v 2 n 2 p 89$

URL: http://dx.doi.org/10.5430/ijh.v2n2p89

\begin{abstract}
Aim: The aim of this study was to explore factors that influence poor adherence to ART among patients at Intermediate Hospital Oshakati in the Oshana region, which is a rural area in Namibia.

Methodology: An explorative, qualitative study was conducted using in-depth interviews among twelve patients $(\mathrm{n}=12)$ identified as poor adherents, which was triangulated with data collected from four key informants (health-workers) in the facility. Eligible participants were purposively selected. Data were audio-recorded and transcribed verbatim. Thematic and content analysis of transcribed data was conducted.

Results: The study results indicated that defaulting ARVs is a huge challenge to HIV/AIDS management. The reasons given by the participants for defaulting were multifaceted and included social factors such as spiritual believe, cultural believes, stigma and discrimination. Patient related factors were also among factors found contributing to non-adherence; these include poor understanding of treatment regimen, forgetfulness, alcohol intake, lack of commitment, travelling and illiteracy.

Conclusions: People living with HIV/AIDS are still facing major challenges, such as stigma, discrimination by family members and people in the community as well as at work and these challenges hamper adherence. In view of this it is recommended that a HIV related program should put more emphasis on reduction of stigma and discrimination in work places as well as in the community.
\end{abstract}

Key Words: Poor adherence, Treatment, Patient, Antiretroviral therapy, Compliance

\section{INTRODUCTION}

The world at large is facing an unrivalled public health crisis. HIV is reported to have reached every corner of the globe and it continues to spread disproportionately fast in marginalized populations in most countries. ${ }^{[1]}$ The number of people living with HIV worldwide continued to grow reaching an estimated 33.3 million (31.4 million - 35.3 million) in 2009 , which was more than $20 \%$ higher than the number in 2000 . It is further estimated that 2.6 million (2.3 million - 2.8 million) new infections and 1.8 million (1.6 million - 2.1 million) AIDS (acquired immune deficiency syndrome) related deaths occurred worldwide in 2009.

\footnotetext{
*Correspondence: Maria Francineth Bauleth; Email: mbauleth@unam.na; Address: Department of General Nursing Science, School of Nursing, University of Namibia (UNAM), P. O. Box 2654 Eliander Mwatale Street, Oshakati, Namibia.
} 
Over the past five years a 10-fold increase of people receiving antiretroviral therapy (ART) has been observed in low and middle income countries which are estimated to be approximately 4 million people. ${ }^{[2]}$ Africa remains the global epicentre of the AIDS epidemic, with Sub-Saharan Africa being one of the worst affected areas in the world. At the end of 2005 about 25 million people were living with HIV and the prevalence rate was about $6 \%$. This number was more than half the global number of those living with HIV. In the SADC region alone, Swaziland had a national HIV prevalence rate estimated at $33.4 \%$, Botswana $24.1 \%$ and Namibia $19.6 \% .^{[3]}$

In 2008 the Namibian population was estimated around 2.1 million $^{[4]}$ of these 230,000 were estimated to be infected with HIV giving a national prevalence of $17.8 \%$ the estimated population life expectancy was 52 years ${ }^{[4]} \mathrm{HIV}$ is considered a public health problem in Namibia since the prevalence ranges from $4.7 \%$ to $31.7 \%$. The Oshana region, where the study was conducted, is one of the regions in the country with a high HIV prevalence rate of $22.4 \%$ among pregnant women. ${ }^{[4]}$

HIV has a major impact on the economy of the country and social progress leading to poverty, a reduction in life expectancy and contributing to food shortage. ${ }^{[5]}$ Although the current HIV sentinel survey in Namibia shows a decline in HIV prevalence from $22 \%$ in 2002 , to $17.8 \%$ in 2008 , HIV still remains the major cause of death in the country accounting for $23 \%$ of all reported deaths and for $41 \%$ of deaths in the age group of 15 to 49 years. ${ }^{[4]}$ A high prevalence of HIV infection in the economically productive age group (25 - 35 years) diminishes productivity and exacerbates food insecurity, making HIV not only a health issue but an economic and development challenge as well. ${ }^{[6]}$ The introduction of ART for HIV patients has dramatically reduced mortality and morbidity as well as improved the quality of life of those infected. ${ }^{[3]}$ According to the Ref., ${ }^{[7]}$ after the introduction of ART in Namibia positive outcomes were noted such as a decrease in hospital admissions from 12,852 in 2004 to 11,410 in 2005; and a decrease in AIDS-related deaths from 36,627 in 2004 to 3,230 in 2005.

According to the Ref., ${ }^{[8]}$ HIV/AIDS was once perceived as a death sentence but with the discovery of more potent and efficacious medicines it is turned into a chronic disease. To ensure maximum ART treatment outcomes, appropriate use of medicines is required as it is imperative that patients adhere to treatment as per doctor's instructions.

In Namibia the use of highly active antiretroviral therapy (HAART) was introduced in the public health sectors in 2003. ${ }^{[4]}$ By the end of December 2010 there were 89,494 patients on ART in public hospitals with adults constituting $89 \%$ and paediatrics $10.2 \%$; it is estimated that at the current growth rate the total number of patients on ART is expected to reach 100,000 by June 2011 . $^{\text {[9] }}$ The government rapidly scaled up the treatment since then, and by 2010 all 44 public hospitals provided ART.

Despite the fact that ART improves many lives of those infected with the HIV worldwide, the ART programs are faced with a major challenge of lack of adherence to treatment. ${ }^{[10]}$ However suboptimal treatment adherence can lead to the virus becoming resistant to the first line medication hastening progress towards full blown AIDS, leading to an increase in the replication of HIV and the development of viral mutations. ${ }^{[1,12]}$ Antiretroviral medication adherence is absolutely vital for the success of HAART. There is consensus that in order to achieve sustained suppression of HIV growth over time, and to prevent the development of drug resistance a very high level of adherence, taking at least $95 \%$ of prescribed doses, is required. Lower levels of ART adherence provide a temporary clinical benefit but pose a very high risk of developing resistance and treatment failure. ${ }^{[12,13]}$ Therefore it is clear that there is a need to take a closer look at treatment adherence.

The first steps towards effective treatment are to make proper diagnoses of the illness and identify the appropriate treatment. However, medication adherence is an equally important component of the treatment because even the most effective medication will not work if taken incorrectly. ${ }^{[14]}$

The introduction HAART in 1996 was a turning point for hundreds of thousands of people who had access to the treatment. Although HAART cannot cure the disease it has dramatically reduced mortality, prolonged lives, and improved the quality of life of many people living with HIV/AIDS. HIV has transformed from a rapidly progressive and universal fatal disease to a chronic and often stable condition. ${ }^{[15,16]}$ Nevertheless treatment efficacy relies on access to treatment and excellent adherence.

\subsection{Problem statement}

According to the Ref., ${ }^{[7]} 95 \%$ of the patients enrolled in the ART programme in Namibia are still alive, $4 \%$ died and $1 \%$ defaulted. At the Intermediate Hospital Oshakati Communicable Disease Clinic 9,549 patients were registered on ART during the period May 2004 to March 2009, and 587 (6.1\%) defaulted from treatment over this period. ${ }^{[17]}$ Since the programme started at IHO there are no documented studies to assess the clients' response to treatment and challenges they face with respect to adherence. Furthermore, the above mentioned situation raises questions about adherence because 
it can be reasonably assumed that poor adherence would precede defaulting, and that an even greater proportion of patients are not adhering optimally, though not altogether lost to follow-up. There is therefore a need to conduct a systematic investigation into the factors that influence adherence among patients in the Oshana District.

\subsection{Research purpose}

The purpose of the study was to describe patients' experiences of living with HIV/AIDS and explored factors that influence adherence to ART amongst patients at Oshakati Intermediate Hospital, Namibia.

\subsection{Research objectives}

The objectives of the study included the following:

- To describe experiences of patients being on ART and living with HIV/AIDS,

- To explore the challenges of patients' socio-economic status/position had on adherence,

- To explore the of role that health care services delivery played on adherence,

- To explore community-related stigma and discrimination and its influence on patient adherence,

- To explore factors related to treatment regimen that influenced adherence behavior.

\section{STUDY DESIGN AND RESEARCH METHODS}

This study was a qualitative, explorative and descriptive in nature. The rationale for using the qualitative approach was to meet its aim; to describe the patient, experiences and to explore the factors that influence adherence to ART. ${ }^{[18]}$ Consider qualitative research designs to suit research that aims to explore health behaviours because qualitative studies place more emphasis on the lived experience of participants in an attempt to understand the phenomenon in its entirety rather than focusing on specific concepts.

\subsection{Study population}

This study consisted of two populations: Firstly, study population included all adult males and females aged 18 years or older who were on ARVs at the selected health facility, namely the IHO and, who were identified as poor adherents by the health-care team. Secondly, the study population was health-workers including doctors, nurses, pharmacist/pharmacist assistant and community counselors, working at the selected health facility.

\subsection{Sampling and sampling size}

Purposive sampling was used to select Patients attending the CDC for follow-up. In-depth interviews were conducted with the 12 participants and their characteristics are presented in Table 1 below.

Table 1. Demographic characteristic of the Participants

\begin{tabular}{|c|c|c|c|}
\hline Characteristic & Female & Male & Total \\
\hline \multicolumn{4}{|l|}{ Age } \\
\hline $27-30$ & 3 & - & 3 \\
\hline $31-40$ & 2 & 4 & 6 \\
\hline $41-50$ & - & 2 & 2 \\
\hline $51-60$ & 1 & - & 1 \\
\hline \multicolumn{4}{|l|}{ Started treatment } \\
\hline 2006 & 1 & - & 1 \\
\hline 2007 & 1 & - & 1 \\
\hline 2008 & 1 & 2 & 3 \\
\hline 2009 & 3 & 4 & 7 \\
\hline \multicolumn{4}{|l|}{ Marital Status } \\
\hline Single & 5 & 3 & 8 \\
\hline Married & 1 & 2 & 3 \\
\hline Co-habiting & - & 1 & 1 \\
\hline Widowed & - & - & - \\
\hline \multicolumn{4}{|l|}{ Employment Status } \\
\hline Employed & 1 & 5 & 6 \\
\hline Unemployed & 5 & 1 & 6 \\
\hline \multicolumn{4}{|l|}{ Co-infected } \\
\hline Not-Co-infected & 3 & 3 & 6 \\
\hline Co-infected with TB & 2 & 2 & 4 \\
\hline Co-infected MDR & - & 1 & 1 \\
\hline Co-infected with other & 1 & - & 1 \\
\hline Total Interviewed & 6 & 6 & 12 \\
\hline
\end{tabular}

\subsection{Data collection}

In this study two different data collection methods were used, namely key informant interviews and in-depth interviews. ${ }^{[19]}$ Considers in-depth interviews as a good tool to use when seeking to learn about people's feelings, thoughts and experiences. In this study in-depth interviews were the primary source of data collection.

\subsection{Data analysis}

In-depth interviews with the participants and key informants were taped and transcribed verbatim to ensure that no information was lost prior to starting data analysis. In this study data analysis commenced as soon as the taped interviews were transcribed and the data were read though over and over to identify emerging themes, categories and sub-categories. The main themes that emerged out of the data analysis of the of the interviews is clustered around the following six themes namely: Social factors, Patient related factors, Health service factors, Socio-economic factors, Work place related factors and Treatment related factors. 


\subsection{Trustworthiness of the study}

Trustworthiness of the whole study was ensured using the criteria of Lincoln and Guba namely: credibility, transferability, dependability, and confirmability of the study. ${ }^{[20]}$ To ensure credibility, the researcher used the triangulation method, ${ }^{[21]}$ whereby the information from the in-depth interviews was triangulated with the information from key informants as well as data from each participant.

The researcher strictly adhered to the selection criteria and only eligible participants were interviewed to ensure credi- bility. A uniform interview guide was developed and used with every participant. With the help of an experienced independent transcriber the interviews were transcribed verbatim to ensure that no data were lost in the process.

\subsection{Ethical considerations}

Ethical clearance was obtained from the University of Western Cape Ethical Committee and permission to proceed while approval was given by the Ministry of Health in Namibia.

\section{RESULTS}

Table 2. Classification of results

\begin{tabular}{|c|c|c|c|}
\hline Themes & Subthemes & Codes & \\
\hline \multirow{2}{*}{ 3.1 Social factors } & 3.1.1 Spiritual beliefs & & $\begin{array}{l}\text { Faith in healing } \\
\text { Traditional therapies }\end{array}$ \\
\hline & 3.1.3 Discrimination & & $\begin{array}{l}\text { Emotional abuse } \\
\text { Depression } \\
\text { Isolation } \\
\text { Rejection by partner } \\
\text { Lack of family support }\end{array}$ \\
\hline \multirow{6}{*}{$\begin{array}{l}3.2 \text { Patient related } \\
\text { factors }\end{array}$} & $\begin{array}{l}\text { 3.2.1 Poor understanding of patient } \\
\text { regimen }\end{array}$ & & $\begin{array}{l}\text { Awareness of the importance of adherence } \\
\text { Knowledge of consequence }\end{array}$ \\
\hline & 3.2.2 Forgetfulness & & \\
\hline & 3.2.3 Alcohol abuse & & $\begin{array}{l}\text { Dangers of alcohol use } \\
\text { Lack of memory } \\
\text { Exposure }\end{array}$ \\
\hline & 3.2.4 Lack of Commitment & & $\begin{array}{l}\text { Networking } \\
\text { Peer group influence } \\
\text { Lack of self-motivation } \\
\text { Unplanned travelling }\end{array}$ \\
\hline & 3.2.5 Travelling & $\bullet$ & Unplanned travelling \\
\hline & 3.2.6 Illiteracy & & \\
\hline \multirow{3}{*}{ 3.3 Health services } & $\begin{array}{l}\text { 3.3.1 Poor patient-health provider } \\
\text { relationship }\end{array}$ & & $\begin{array}{l}\text { Lack of empathy } \\
\text { Lack of trust } \\
\text { Negative attitudes of health providers }\end{array}$ \\
\hline & $\begin{array}{l}\text { 3.3.2 Overcrowding and disorganization } \\
\text { at the clinic }\end{array}$ & & $\begin{array}{l}\text { Lack of order } \\
\text { Long waiting times }\end{array}$ \\
\hline & 3.3 Long distance to health facility & & \\
\hline \multirow{3}{*}{$\begin{array}{l}\text { 3.4. Socio economic } \\
\text { factors }\end{array}$} & 3.4.1 Unemployment & $\bullet$ & Work related migration \\
\hline & 3.4.2 Unavailability of transport & & \\
\hline & 3.4.3 Floods & & Inaccessible to health facility \\
\hline \multirow{2}{*}{$\begin{array}{l}\text { 3.5 Workplace related } \\
\text { factors }\end{array}$} & 3.5.1 Work related pressure & & \\
\hline & 3.5.2 Lack of support from employees & & \\
\hline \multirow{3}{*}{$\begin{array}{l}\text { 3.6. Treatment related } \\
\text { factors }\end{array}$} & 3.6.1 Treatment side effects & & \\
\hline & 3.6.2 Treatment fatigue & & \\
\hline & 3.6.3 Complexity of the treatment process & $\bullet$ & Too much counselling \\
\hline
\end{tabular}




\subsection{Social factors}

In this study social factors such as spiritual beliefs, cultural beliefs, stigma and discrimination, were reported to have had negative effects on participants' adherence to medication and compliance with the health regimen.

\subsubsection{Spiritual beliefs}

Religious and cultural beliefs such as having faith in healing and reliance on traditional therapies had detrimental effects on adherence.

\section{- Faith in healing}

Some participants reported that when they sought advice from friends, they advised them to rely on their faith instead of the medical or health care system. Participants, who turned to religion (a church) for support, were often advised by fellow church members to rely on God only. This led to some of them defaulting on their treatment in solidarity to the faith.

“...Most churches are misleading they are telling people to stop taking their treatment so that they can pray for them to get healed..." (Key informants)

\section{- Traditional therapies}

Patients with strong cultural beliefs first seek traditional healers' opinions before consulting health-workers. The traditional healers, in turn, convince them that they are bewitched and can only be cured with traditional medications.

“... most of my relatives don't know how to read and write just like me. When I became sick, they took me to the traditional healers..." (Female 37yrs)

\subsubsection{Stigma}

Stigma in the community and from family members has impaired adherence to treatment since this causes affected persons to experience negative emotions, fear of disclosing HIV status and unwillingness to take ART in the presence of others.

\section{- Emotional disturbance}

Some patients reported being depressed and unhappy because people from their location were gossiping about their HIV status. One participant claims to have reported those gossiping about his HIV status to traditional authorities, which resulted in those involved being referred to traditional courts.

“... Community people should be left like that. Anyway nobody will stop them from gossiping about us who are HIV positive, and you know what? They enjoy when others are suffering... It really hurts a lot, sometimes I spend sleepless nights because of that." (Female 40+yrs)

Published by Sciedu Press

\section{- Non-disclosure of HIV status}

Fears of stigmatization led to some participants selecting who to disclose their HIV status to. Patients feared their HIV status would be known by people in the community therefore they kept it a secret even from their partners.

“...It is only I and my sister who know my HIV status; not even my girlfriends are aware. People in the community will laugh at you and makes your life impossible if they happen to know your HIV status." (Male 36yrs)

\section{- Unwillingness to take ART in the presence of others}

Participants reported that they would rather not take their treatment than take it in the presence of friends and acquaintances.

“... I get lots of visitors if they pay me a visit the time I was supposed to take my medications It becomes difficult for me to take them because they may suspect that I am on treatment..." (Female 35yrs)

\section{- Patients accessing treatment at clinics far from home}

Stigmatization also led some participant to access medical treatment at clinics that are far from their homes to avoid being seen by people known to them when they go for followup appointments.

"Sister, here we get people from Omuthiya, which is more than a 100km from here. Leaving Omuthiya clinic behind, but what can we do? It is their rights Sister. Patients are afraid to be rejected by people in the community." (Key-informant)

\section{- Lack of social support}

According to the key-informants, most patients experience difficulties in obtaining assistance from treatment supporters because the eligible ones refuse to come and accompany them to the clinic.

"Most people find it difficulties to get treatment supporters because those that are close to them refuses to come with them to the clinic."

\subsubsection{Discrimination}

Discrimination in the community, as well as amongst family members, has contributed to impaired adherence due to emotional abuse, depression, isolation, rejection by partner as well as lack of family support.

\section{- Emotional abuse}

One of the participants complained that he was insulted by his wife's relatives and accused of transmitting HIV to her.

"I was very annoyed when a school boy a relative to my wife insulted me and accused me of infecting my wife with the 
HIV... ” (Male 36yrs)

\section{- Depression}

The initial reaction to the HIV test result led to shock and depression, one participant reported that she almost committed suicide and another said that she wished to die because of being teased by relatives because she was HIV positive.

“... When people at home tease me because of my HIV status, I wish to die so that I can leave them in peace with their things..." (Female 40+yrs)

\section{- Isolation}

One participant claimed that people in the community keep a distance from him because of HIV related symptoms which makes him feel uncomfortable and rejected.

"One of my sisters has not accepted my HIV status; she blames me that I have done the biggest mistake of my life..." (Female 27yrs)

\section{- Rejection by partner}

Being HIV positive has contributed to mistreatment by partner and relatives resulting in patients defaulting treatment. One participant cited being left by her boyfriend the day she revealed her HIV status. Some relationships ended because of partners blaming each other.

“... My boyfriend left me the day I revealed my HIV status to him. Some of my friends are keeping a distance because they found out that I was HIV positive. . " (Female 27yrs)

Some of the key-informants confirmed that mistreatment from spouses is common as most patients who defaulted complain of being neglected by a spouse or even being chased out of the house when their HIV status became known.

"Mistreatment from the spouse is very common. Some husbands tend to neglect their wives or even chase them from their houses if they find out that they are HIV infected, even if both of them are infected, this leads to depression and in turn to poor adherence."

\section{- Lack of family support}

The defaulters claimed they were disappointed with lack of family support since some of their family members kept their distance, which discouraged HIV positive persons to disclose their HIV status.

“... Some of my relatives and friends kept a distance when they heard that I was suffering from HIV, they no longer pay me a visit..." (Female 29yrs)

All key-informants confirmed that many defaulters had poor support from their families and communities where they lived. According to the key-informants this was evidenced by those brought in by their relatives/friends to hospital and left alone at the clinic.

\subsection{Patient-related factors}

Individual factors relating to the patient, such as, poor understanding of the treatment regimen, forgetfulness, alcohol use, lack of commitment, personal beliefs, non-disclosure of HIV status, travelling and illiteracy influenced adherence, led to defaulting on ART in some cases.

\subsubsection{Poor understanding of treatment regimen}

Awareness of the importance of adherence as well as knowledge of the consequences of poor adherence, contributed to participants defaulting their treatment.

\section{- Awareness of the importance of adherence}

Lack of understanding of the importance of treatment adherence contributed to patients dropping the treatment when they were feeling better. Participants reported they stopped taking treatment after they started feeling better.

"When I started taking the ARTs, I only took them for a week or more then I threw them away since I started feeling better. I thought it was no longer necessary to take them... " (Male 36yrs)

\section{- Knowledge of consequences of poor adherence}

Some participants agreed that they did not have sufficient knowledge about the importance of taking medications on a regular basis. They reported discontinuing ART after experiencing side-effects. They also cited medications not well explained to them; thus leading to poor adherence.

“... At first the medications were not well explained to me. I think I did not understand everything. That is why when they made me feel sick, I stopped taking them... " (Male 36yrs)

\section{- Leftover pills}

According to one of the key-informants, patients ignore their follow-up dates and continue taking left over medications. Two pills are given in excess at the pharmacy every month, patients keep and take them and ignore their follow-up dates.

“... I had to travel to Windhoek urgently hoping not to stay for long. After all I had some left over pills, I was not worried but unfortunately I overstayed. My pills got finished and I also missed my appointment date...” (Female 27yrs)

\subsubsection{Forgetfulness}

An overwhelming number of participants cited forgetfulness as a factor that contributed to poor adherence to medications especially when doing other tasks. Concentrating on work tasks contributed to forgetting to take medication at the 
prescribed times.

“... At work when I get preoccupied most of the times I forget to take my treatment, when I remember it is too late..." (Male 36yrs)

\subsubsection{Alcohol use}

Some of the participants mentioned that using alcohol was a barrier to treatment adherence because alcohol contributes to their lack of memory. Participants also reported that work related exposure contributed to alcohol use which in turn led to treatment defaulting.

\section{- Difficulties to stop using alcohol}

One of the defaulters claimed to have been a heavy drinker before starting ARVs and is finding it very challenging to stop drinking.

“... I was a true drinker. It is such a big challenge to stop taking alcohol...” (Male 41yrs)

\section{- Lack of memory}

Alcohol intoxication impairs memory and leads to forgetfulness or ignorance of the time to take medications. This is confirmed by one of the participants in the current study who claims to be more forgetful after he consumes alcohol.

"Sister having some few drinks with friends or alone makes me forget about taking my medications, -even if I am carrying them with me. I only remember the next day... " (Male 36yrs)

\section{- Exposure}

Some participants cited finding it difficult to stop using alcohol because of peer influence. In addition bar attendantswho are on ARVs also face challenges in avoiding to take alcohol when customers buy alcohol for them.

"I work in a bar, most of the times I am tempted to take some alcohol and forget to take my pills..." (Female 37yrs)

\subsubsection{Lack of commitment}

Lack of commitment to ART has contributed to poor adherence. This is evident in some participants failing to take their treatment because of networking and peer-group influence. Some simply lacked self-motivation.

\section{- Networking}

One of the participants reported that just thinking about socializing with friends as well as actively socializing often results in defaulting.

"I like to enjoy with friends, when I go out with them hoping not to stay for long I find myself spending the whole day or even a weekend without taking my pills..." (Female 27yrs)

\section{- Peer group influence}

Peer group influence is reported to have affected one of the participant's decision making who said that he agreed with a friend not to go back for ARTs until they have fallen sick.

"I only went for HIV test when my best friend Titus requested me to escort him to the clinic to do an HIV test." (Male 36yrs)

\section{- Lack of motivation}

Most of the participants defaulted on their treatment because of lack of motivation. For example those who misplaced their health passport did not inform the health-workers of the problem but instead waited for the misplaced item to be found at some stage.

“... I defaulted for two months because my baby was admitted in ward 10 and a lady whose child was also admitted in the some ward and room with my child and whose baby was discharged earlier than mine she had mistaken her bag with mine and left with my bag where I placed my health passport... there is nothing I could do". (Female 29yrs)

\subsubsection{Travelling}

Participants' who travel a lot reported that unplanned travelling contributed to treatment defaulting and poor adherence.

\section{- Unplanned travelling}

Participants are faced with challenges such as unplanned travelling with friends or even work related commuting. This was supported by one of the key-informants who said that the defaulters reported that when traveling they sometimes forget their medications at home leading to treatment defaulting.

“... Clients give several excuses of going to attend funerals or of travelling ..." (Key-informant)

\subsubsection{Illiteracy}

Some of the defaulters indicated that they cannot read the instructions in their health passports and are unable to remember what has been said to them by the health-workers. Instead they depend on those who live with them who in turn tell them to wait until they run out of medication while waiting for the next appointment date; this also contributed them to missing their appointments and being poor adherents.

"... I think those that I am living with and claim to know how to read and write are also just like me," illiterate," how come they always tell me wrong dates?.." (Male 46+yrs)

\subsection{Health service factors}

Participants cited various health system factors that were negatively affecting adherence, namely: poor patient provider relationship, overcrowding and disorganization at the clinic, long queues, the attitudes of health providers, and long dis- 
tance to health facility.

\subsubsection{Poor patient-health provider relationship}

Although participants reported to be generally satisfied with the quality of care at the health service facility, some reported that the patient-health provider relationship was characterized by lack of empathy, lack of trust and negative attitudes of HCPs.

\section{- Lack of empathy}

Some defaulters reported HCPs' attitudes to be unfriendly, not very helpful and they do not pay attention to their problems, which contributed to them being non-adherent to their treatment.

"...I asked the doctors several times to give me a transfer later to the nearby clinic but they are taking too long. Imagine it's now a year that I am struggling to get that letter..." (Female 28yrs)

\section{- Lack of trust}

According to some participants, the negative client-provider relationship contributed to lack of trust and eventually influenced the adherence of patients negatively. Participants reported some HCPs do not pay attention to what they are telling them and cited doctors and nurses giving them unpleasant answers.

“Doctors and nurses don't understand my problems they always think I am laying when I am telling them the problems I am having that cause me to default..." (Female 28yrs)

\section{- Negative attitudes of health providers}

Most defaulters were dissatisfied by the negative attitudes of the nurses. Those who default their treatment feared to go back to the clinic. Defaulters cited nurses and doctors being very rude to them and these negative attitudes of the HCPs are demotivating thus contributing to non-adherent behaviour.

“... some of the nurses and doctors at the clinic are very rude; the way they talk to us is not good it makes me feel very unwelcome....... When I defaulted my treatment I became extremely scared I feared this rude nurses, it is my family who brought me back when I became sick....” (Female 27yrs)

\subsubsection{Overcrowding and disorganization at the clinic}

Most of the defaulters highlighted overcrowding at the clinic to have contributed to some of the participants leaving the clinic without being attended to, due to other commitments. They complained about the noise at the clinic that makes it difficult to hear their names when called by HCPs. This contributed to being attended to very late and eventually leaving without medications.
"I do afternoon shifts until midnight and because of the delay at the clinic most of the times I go to work late and very exhausted because there is no time to rest... because this clinic is always very full." (Male 46+yrs)

\section{- Lack of order}

The majority of participants listed lack of order at the clinic to have contributed to disorganization, since young people who come late to the clinic squeeze themselves in front of elderly people who come very early to the clinic.

“....most people who come from very far and who could have come early to this clinic end up being treated last and living without their treatment because when you reach the pharmacy you will find it closed that has happened to me several times...." (Male 36yrs)

\section{- Long waiting time}

A few defaulters raised complaints about long queues at the clinic. The waiting times were very long and contributed to them becoming frustrated and eventually defaulting their treatment.

“... This clinic is always very full, it is really discouraging...people working at the clinic are very slow, I would like them to change their speed, because of their speed you will find the pharmacy closed that has happened to me several times...." (Male 46+yrs)

\subsubsection{Long distances to health facility}

Most participants highlighted that they come from very far. They cited distance to the clinic and not having money for transport as a key problem to adhering to follow-up appointments.

“... I don't have a job and I travel as far as from Okahao to get my medicines. Most of the times I don't have money for transport but once in a while my friends as well as my family, when they have money they help me out..." (Male 30yrs)

\subsection{Socio-economic factors}

Socio-economic factors that have emerged from the study and negatively affected adherence were: unemployment, lack of transport and floods.

\subsubsection{Unemployment}

Unemployment was a key factor that caused defaulting on treatment among some participants. It contributed to some participants not being able to afford buying food to take with medication. Factors such as lack of transport money and work related migration also contributed to poor adherence.

“... I am not employed, my family depends on me only and on our millet field but sometimes the rainfalls is poor and I 
just don't have enough food to take those pills and also don't have money to buy food or to go to for follow-up visits..." (Male 39yrs)

\section{-Work-related migration}

Some of the defaulters claim they could not find employment in Namibia and ended up working in a neighbouring country, such as Angola, hence they cannot afford to return regularly for monthly follow-ups.

“...I work in Angola and at work it is compulsory for me to stay there for two months to be given day-offs, this makes life difficult because I am supposed to come for follow-ups every month..." (Male 41yrs)

\subsubsection{Unavailability of transport}

Defaulters from villages far away from Oshakati (the town where CDC is located) reported it was difficult finding transport to the hospital. There is no public transport and very few people own cars in their villages. Thus they have to rely on other villagers who own vehicles to transport them to hospital.

"Sister at our village there is just one Car that comes to Oshakati (the town where CDC is located) if the car breaks down what can I do? And the car only comes once a week, definitely I will miss my appointment." (Male 36yrs)

\subsubsection{Floods}

Most participants cited floods as having contributed to them not being able to access the health facilities leading to them defaulting treatment. When it rains most of the villages in the Oshana Region, where the study was conducted, become encircled by the flood waters making it completely impossible to reach or leave those areas.

“......We sometimes reach those places with an helicopter that is being utilized for PHC services but for the past two years we have not done so, we don't carry outreach services, we don't even have enough staff or transport to carry out such services." (Key-informant)

\subsection{Work place factors}

Participants mentioned work related pressure and their respective employer's lack of support as hindering factors for good adherence. Patients do not disclose their HIV status for fear of losing their jobs.

\subsubsection{Work related pressure}

Participants claim to be challenged by work related pressure, such as discrimination and fear of losing their jobs. The defaulters felt that disclosing their HIV status to their employers and colleagues might contribute to discrimination in the work place.

Published by Sciedu Press
"...... my boss is not aware about my HIV status. This makes things more difficult because he will not understand why I should go to hospital every month. I fear to tell him because maybe he is going to fire me...." (Male 36yrs)

\subsubsection{Lack of support from employers}

Participants cited lack of encouragement from their bosses and work related travel as factors that affected non-adherence. Participants reported their bosses did not encourage them to take their treatment and some made them to be disqualified from being given ARTs because they followed them to the clinic and forced them to leave the clinic unattended which contributed to poor adherence.

“... my boss is somebody who doesn't understand his employee's problems, what matters to him is only his work..." (Male 41yrs)

One of the key-informants reported to have experienced employers following their employees to the clinic and making them leave the clinic without being attended to.

"My dear, I have come across employers coming to our clinic to ask the doctor what is wrong with their employees, because they themselves are not free to tell, I have also come across those who lose their jobs after their bosses found out that they were HIV positive." (Male 37yrs)

\subsection{Treatment related factors}

Some defaulters cited treatment side-effects, treatment fatigue as well as complexity of the treatment process as hindering factors for good adherence.

\subsubsection{Treatment side-effects}

Some participants reported discontinuing medications as a result of adverse drug effects such as vomiting, nausea, mental confusion and skin rashes.

"Some of the clients have stopped taking the medications because of the drugs negative effects." (Key-informant)

\subsubsection{Treatment fatigue}

Participants reported pill burden to negatively influence adherence as participants who are on combined treatment said they are tired of treatment.

“... I always force myself to take those tablets.... sometimes I just feel tired to take those pills imagine taking both TB and those for HIV?" (Male 36yrs)

\subsubsection{Complexity of the treatment process}

According to some defaulters the challenges they encountered taking ARTs were exacerbated by the complexity of the ART regimen that requires one to undergo a long process of counselling.

\section{- Too much counselling}


Participants reported to have failed to tell the health-workers the truth about their defaulting behaviour because they feared their treatment would be stopped and they would restart the lengthy treatment initiation process before the treatment is restarted.

"When I went to hospital for the first time I thought I will get the medications the same day but I was disappointed to find out that the process is so complex. I was given several follow-ups until I gave up, I had to restart the same process again...." (Male 36yrs)

\section{Discussions}

In discussing these findings, it emerged that some ARVs defaulters where convinced and believed that they were bewitched or that their disease could only be treated with traditional medicine. They admitted to having stopped their treatment and to have sought help from traditional healers. In a study done in Botswana by Ref., ${ }^{[22]} 47 \%$ of the patients interviewed acknowledged the use of traditional remedies for HIV infection and $21 \%$ anticipated visiting a traditional healer in the future for treatment the disease.

This study also found that some participants stopped taking their medications because of religious beliefs and influences. Although, according to Ref., ${ }^{[23]}$ the literature suggests that church attendants and spiritual believers are more likely to adhere to treatment. However some religious beliefs can have a negative impact on adherence due to stigma associate with HIV/AIDS.

The study findings also showed that some participants failed to take their treatment in the presence of friends or to discuss their illness with families and neighbours for fear of what others might say and suspect. These findings are in line with what is reported by Ref., ${ }^{[2]}$ namely that if patients are seen taking ART by family members, neighbours, or friends, this is likely to convey a signal that they are HIV positive and living with AIDS. The negative influence that social support has on ART adherence as shown in this current study has been well documented. ${ }^{[22,25]}$ Some participants reported that the behaviour of community members, as well as family members, changed towards them when they found out about their HIV status.

The current study identified that poor knowledge, or a lack thereof, about ARV treatment as being a leading factor that contributed to treatment defaulting. Some of the defaulters interviewed in this study reported to have defaulted after they felt better; they thought that they need to only take medications when they were not feeling well. According to Ref. ${ }^{[24]}$ behavioural obstacles, such as stopping drugs when symptoms disappeared, have been reported in studies done in Sub-Saharan regions as well as elsewhere. Similar trends were noticed in Botswana, by Ref., ${ }^{[22]}$ where $8 \%$ of the patients stopped treatment as soon as their symptoms disappeared.

Alcohol abuse is a factor that hinders adherence in terms of the findings of this study. Some participants cited alcohol intake as causing them to forget to take their medications. According to a systematic review conducted by Ref. ${ }^{[26]}$ alcohol intake was amongst the factors reported to negatively impact on adherence in developing countries. More recent studies of patients who were receiving multidrug regimens suggest that use of alcohol is associated with non-adherence. ${ }^{[27]}$

One of the critical issues that emerged from the study is poor literacy. Some of the participants claim to be completely illiterate while most of them have very low levels of education and cannot communicate in English (the official language in Namibia). They therefore lacked the ability to read the instructions given by the HCPs which in turn contributed to them not adhering to treatment or to follow-up appointments. These findings are in line with those from a cohort study by Ref., ${ }^{[28]}$ who followed patients on a new ART regimen for 48 weeks and reported low health literacy to be associated with poor knowledge of the regime and they concluded that low health literacy was a barrier to adherence early in the course of treatment.

Some participants in the current study raised concerns about having to cover long distances to the health facility especially since there is lack of public transport. Long distances to facilities that provide ARVs remains a crucial issue to ARV defaulting. According to Ref., ${ }^{[29]}$ distance, transport, and finance, were found to be barriers to adherence. In this study participants claim to have defaulted treatment because of floods that are common in the area during raining seasons. According to Ref. ${ }^{[30]}$ there are a huge range of different crises that can potentially undermine ART treatment. For example, the 2008 floods in Mozambique are known to have contributed to several health related problems including poor access to health care.

The financial difficulties experienced by the population group in this study are important as most people who attend the clinic are unemployed and are from far villages. Financial difficulties were commonly cited as a reason for not returning for clinic visits or for defaulting treatment. These finding are in line with those reported by Ref. ${ }^{[31]}$ since in a study done in Bolivia it was found that patients who defaulted their treatment claimed not to have money for transport to health facilities.

In the current study it emerged that treatment side-effects 
impacted on treatment defaulting. Some patients reported to have stopped taking their treatment because of some drug related side-effects. These findings are in line with a study conducted in Botswana by ${ }^{[22]}$ which indicated that side-effects pose a major barrier to treatment adherence.

\section{Conclusions}

Based on the findings of this study several interrelated factors were found to contribute to non-adherent behaviour at the selected health facility in the Oshakati district. This study highlighted spiritual beliefs as a contributory factor as some patients stopped taking their treatment in solidarity to their faith or in favour of traditional medicine. Furthermore stigma and discrimination led to some participants not disclosing their HIV status which meant they accessed treatment at clinics far from their homes and in some instances participants feared that disclosure of their status could result in them being rejected by their respective partners which in turn influenced adherence negatively. Alcohol abuse and forgetfulness were amongst the factors reported to have contributed to nonadherent behaviour. Illiteracy as well as lack of knowledge about the treatment regimen was barriers that could be linked to personal and health service factors.

\section{Recommendations}

The following recommendations are made based on the findings of the study:

- Continuous in-service training for health-care workers on customer care, professionalism and on the develop- ments concerning HIV/AIDS adherence should be provided.

- The nurse training curricula could also be reviewed to evaluate the inclusion and adequacy of content in customer care and ARVs.

- HIV/AIDS needs to be integrated into normal health care services to curb stigma and discrimination in the community as well as at the health facility.

- The government should provide grants where appropriate to assist the clients to meet dietary adherence requirements.

- The Ministry of Health and Social Services should provide transport for ARV outreach programmes; during the rainy seasons when there are floods a helicopter should be provided to reach inaccessible places and monthly outreach services should also conducted.

- The number of the nurses and pharmacist assistants should be increased to attain quality of adherence services as well as to conduct outreach services.

\section{ACKNOWLEDGEMENTS}

We wish to thank all the respondents who took part in this study. Without their participation this study would not have been even a success or even possible.

\section{CONFlicts of InTERest Disclosure}

The researchers declare that they had no financial or personal relationship(s) which may have inappropriately influenced them in the writing of this article.

\section{REFERENCES}

[1] WHO, UNAIDS \& UNICEF. Towards Universal Access: Scaling up Priority HIV/AIDSIntervention in the Health Sector. Progress Report 2009. Geneva: World Health Organization; 2009. Available from: http://www. who.int/hiv/pub/2009progressre port/en/index.html

[2] UNAIDS/WHO. AIDS epidemic update December 2009. Geneva: Switzerland. 2009.

[3] UNAIDS. Report on global AIDS epidemic. Geneva: Joint United Nations Programme on AIDS. 2006.

[4] Ministry of Health and Social Services. Report on the 2008 National HIV Sentinel Survey 1992-2008. Republic of Namibia. 2014.

[5] Jackson H. AIDS Africa continent in crisis. Harare: SAFAIDS. 2002.

[6] UNAIDS. Report on global AIDS epidemic. Geneva: Joint programme of HIV/AIDS. 2008. Available from: http://data. una ids.org/pub/GlobalReport//2008.

[7] Ministry of Health and Social Services. Coverage and funding gaps in Namibia HIV/AIDS response. Republic of Namibia. 2006.

[8] Ministry of Health and Social Services. National guideline Policy on HIV/AIDS. Republic of Namibia. 2007a.
[9] Ministry of Health and Social Services. Quarterly ART Services feedback Report. Quarter 3 FY 2010/11. Republic of Namibia. 2010.

[10] World Health Organization. Adherence to long-termtherapies: Evidence for action. Geneva: World Health Organization. 2003. Available from: http://www. emro. who.intel/ncd/publications

[11] Ministry of Health and Social Services. Coverage and funding gaps in Namibia, HIV/AIDS response. Republic of Namibia. 2006.

[12] Castro A. Adherence to antiretroviral therapy. Merging the clinical and social course of AIDS. Plos Medicine. 2005; 2(12): 338 http://dx.doi.org10.1371/journal.med.0020338

[13] Ministry of Health and Social Services. National guideline for antiretroviral therapy. Republic of Namibia. 2007b.

[14] Bogart LM, Kelly JA, Catz SL, et al. Impact of medical and nonmedical factors on physician decision making for HIV/AIDS antiretroviral treatment. Journal Acquired Immune Deficiency Syndrome. 2000: 23(5): 396-404. http://dx.doi.org/10.1097/00126334-200 004150-00006

[15] Arnsten JH, Li X, Mizuno Y, et al. Factors associated with antiretroviral therapy adherence and medication errors among HIV infected injection drug users. J. Acquired Immune Def. Syndrome. 
2007; 46: S64-S77. http://dx.doi.org/10.1097/qai.0b013 e31815767d6

[16] Mills EJ, Nachenga JB, Bangsberg DR, et al. Adherence to HAART: A systematic review of developed and developing nation patientreport barriers and facilities. 2006.

[17] Oshakati Health Information System (HIS) Namibia. Communicable Disease Clinic. Intermediate Hospital Oshakati, Namibia. 2008.

[18] Pope C, Ziebland S, Mays N. Analyzing qualitative data. British Medical Journal. 2000; 320: 114-6. PMid: 10625273. http://dx .doi.org/10.1136/bmj.320.7227.114

[19] Bowling A. Research methods in health: Investigating health and health services. (2nd Edition) United States of America. 2002.

[20] Polit DF, Becker CT. Nursing Research: Nursing research generating \& Assessing Evidence for nursing practice. Lippincott williams \& Wilkins. Ninth edition; Philadephia: USA. 2012.

[21] Gifford S. Qualitative research methods. The soft option? Health promotion. Journal of Australia. 1996; 6: 58-6.

[22] Weiser S, Wolfe W, Bangsberg D, et al. Barriers to antiretroviral adherence for patients living with HIV infection and AIDS in Botswana. J. Acquir Immune Defic Syndrome. 2003; 34: 281-8. http://dx.doi .org/10.1097/00126334-200311010-00004

[23] Parsons SK, Cruise PK, Davenport WM, et al. Religious beliefs, practices and treatment adherence among individuals with HIV in the Southern United States. AIDS Patient Care and STDs. 2006; 20(2): 97-111. PMid: 16475891. http://dx.doi.org/10.1089/apc. 2 006.20 .97

[24] Ware NC, Idoko J, Kaaya S, et al. Explaining adherence success in Sub-Saharan Africa: An ethnographic study. 2009; PMid: 19175285. http://dx.doi.org/10.1371/journal.pmed.1000011
[25] Remien RH, Hirky AE, Jonson MO, et al. Adherence to medication treatment: A qualitative study of facilitators and barriers among a diverse sample of HIV+men and women. United State of America: Four Cities. AIDS and Behavior. 2002; 7(1): 61-70. http://dx.doi.org/10.1023/A:1022513507669

[26] Nachenga JB, Mills EJ, Schecheter M. Antiretroviral therapy adherence and retention in care in middle-income and low-income countries: Current status knowledge and research priorities. Current opinion in HIV and AIDS. 2010; 5: 70-7. PMid: 20046150 http://dx.doi.org/10.1097/COH.0b013e328333ad61

[27] Gilfford AL, Bormann JE, Shively MJ, et al. Predictors of selfreported adherence and plasma HIV concentrations in patients on multidrug antiretroviral regimens. JAIDS Journal of Acquired Immune DeficiencySyndromes. 2000; 23(5): 386-95. http://dx.doi . org/10.1097/00126334-200004150-00005

[28] Paasche-Orlow MK, Cheng DM, Palepu A, et al. Health literacy, Antiretroviral Adherence and HIV-RNA Suppression. J GEN INTERNMED. 2006; 21: 835-40. PMid: 16881943. http://dx.doi .org/10.1111/j.1525-1497.2006.00527.x

[29] Nakinyemba A, Kweza R, Akurat D. Barriers to Antiretroviral Adherence for Patients living with HIV infection and AIDS. Busago University: Uganda; 2004.

[30] Veenstra N, Whiteside L, Laloo D, et al. Unplanned antiretroviral interruptions in South Africa: how should we be managing these? Globalization and Health. 2010; PMid: 20356383. http: //dx.doi.org/10.1186/1744-8603-6-4

[31] Greene JA. An ethnography of non-adherence: culture poverty and tuberculosis in urban Bolivia. Cultural Medicine Psychiatry. 2004; 28: 401-25. http://dx.doi.org/10.1023/B:MEDI. 000004642 $9.55801 . c 8$ 